\title{
HVAC SYSTEMS HEAT RECOVERY WITH MULTI-LAYERED OSCILLATING HEAT PIPES
}

\author{
KABÁT Juraj ${ }^{1 \mathrm{a}}$,GUŽELA Štefan ${ }^{1 \mathrm{~b}}$, PECIAR Peter ${ }^{1 \mathrm{c}}$ \\ ${ }^{1}$ Slovak University of Technology in Bratislava, Faculty of Mechanical Engineering, \\ Institute of Process Engineering, Námestie Slobody 17, 81231 Bratislava, Slovakia,

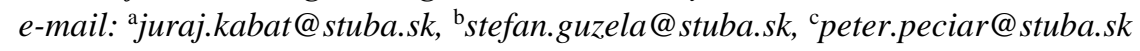

\begin{abstract}
The aim of this work is to investigate a heat performance of a Multi-Layered Oscillating Heat Pipes Heat Exchanger (ML-OHPHE) for the application of heat recovery in heating, ventilation and air conditioning systems (HVAC systems). The heat exchanger is investigated experimentally under different conditions of heat loads and filling ratios. The experimental data results are compared to the data obtained from Honeywell's UniSim ${ }^{\circledR}$ Design Suite software. In the end the NTU analysis of the ML-OHPHE is done and a value of overall heat transfer coefficient is calculated. The results of the experiments indicate that the ML-OHPHE could serve as a completely passive heat transfer device in the application of heat recovery in HVAC systems.
\end{abstract}

KEYWORDS: multi-layered oscillating heat pipes, OHP, heat exchanger, HVAC, heat recovery system, NTU method

\section{Introduction}

Heat recovery represents a basic tool for reducing energy consumption in heating, ventilation and air conditioning (HVAC) systems. The most important part of each heat recovery system is the heat exchanger $[1,18]$. Oscillating (or pulsating) heat pipes - OHP originally presented by Akachi provide new possibilities for heat transfer devices thanks to their unique two-phase heat transfer mechanism [2].

The OHP is generally formed of interconnected meandering capillary tubes partially filled with a working fluid. Heat from an external heat source causes the working fluid to partially evaporate, so the vapour and liquid coexist in the closed system. Thanks to the surface tension of the working fluid and the small inner diameter of the tube channel, vapour and liquid phases form into a train of separate vapour bubbles and liquid plugs. Heat removed from the OHP by an external heat sink forces the vapour bubbles to condense. Periodic evaporation and condensation of the working fluid initiate pressure pulsations in the closed system, serving as a driving force for a thermally excited oscillating motion of the working fluid characteristic for OHP [3]. The typical OHP is divided into 3 sections. The evaporating section represents the part of the OHP where the heat is added into the working fluid from the external heat source, while the condenser section represents that part of the OHP where the heat is removed from the working fluid by an external heat sink. The part of the OHP between the evaporating and condenser section is called the adiabatic section.

Many recent applied experimental research projects have proved the different possibilities of the OHP applied to various heat transfer applications such as electronics cooling and heat spreaders or thermal management and heat exchangers [4, 11]. Supirattanakul et al. successfully decreased energy consumption of an air conditioning system by integrating the OHP heat exchanger [5]. Rittidech et al. designed and tested the OHP air preheater for heat recovery and reduction of relative humidity in drying systems [6, 7]. Mahajan et al. 
theoretically investigated the annual energy cost saving potential of the OHP for air-to-air heat recovery in an air conditioning system and consequently fabricated the OHP heat exchanger for heat recovery in HVAC systems [8, 9, 17]. McCullough et al. theoretically investigated the NTU (number of transfer units) heat transfer analysis of the OHP heat exchanger [10].

There are several factors affecting the OHP heat transfer capability, such as thermophysical properties and the filling ratio of the working fluid, the external heat load and heat sink, the inner diameter of the channels or the number of turns and geometric arrangement. Although it is indisputably clear that the filling ratio, which is defined as the ratio between the working fluid volume in the liquid state and the total inner volume of the OHP channels, strongly affects the OHP heat transfer capability, a universal optimal value has not yet been established. It can be generally stated that the OHP should successfully operate within a filling ratio range of from $20 \%$ to $80 \%$ [12-15]. Qu et al. investigated the effect of the number of OHP layers [16]. The OHP arranged in a number of layers of serpentine channels showed better heat transfer performance in comparison with a one-layer OHP.

This article is aimed at testing the heat transport capability of a heat exchanger equipped with multi-layered OHP placed in a HVAC heat recovery testing rig. Total heat transferred by the heat exchanger is observed under different conditions of filling ratio and different loads of volumetric flow rates of the air flowing in a testing rig.

\section{The HVAC testing rig}

The HVAC testing rig is schematically illustrated in Fig 1. The rig consists of two separated air duct loops - the heated air loop and the cooled air loop. The loops are situated in parallel and the heated air loop is placed under the cooled air loop. The testing section of the rig is made up of a $250 \times 200 \mathrm{~mm}$ rectangular shape duct. The ML-OHPHE is located vertically in the middle of the testing section. Both the loops are equipped with one radial fan (DALAP TURBINE M Ø150mm). The fan's air flow is controlled and set by the attached frequency converters. The volumetric air flows in the both loops are calculated based on the flow velocity. The flow velocity in the both sections are measured by two hot-wire velocity probes (air velocity range from $0 \mathrm{~m} / \mathrm{s}$ to $30 \mathrm{~m} / \mathrm{s}$ ) which are attached to a multifunction sensor (model KIMO C310). Both hot-wire velocity probes were calibrated using turbine flow meter, model Elster TRZ DN100 G400.The fans are connected to the testing section by an $\varnothing 100 \mathrm{~mm}$ air duct. The heated air loop is equipped with a $0,9 \mathrm{~kW}$ electric air heater (EKA NV 100-0.91f) with integrated temperature regulation within a temperature range of from $0^{\circ} \mathrm{C}$ to $30^{\circ} \mathrm{C}$. The electric heater is located downstream to the fan. The cooled air loop is equipped with a finned tube air cooled heat exchanger. The finned tube heat exchanger is connected to a refrigerated water bath (HAAKE K15 type with HAAKE DC30 control) with a cooling liquid temperature range of from $-28^{\circ} \mathrm{C}$ to $150^{\circ} \mathrm{C}$. The temperatures of the flowing air in both loops of the rig are measured by the coated thermocouples connected to a DAQ system and evaluated by a PC. The thermocouple measure points are located in both loops in the centre of the testing section. The air humidity in the both loops is measured by temperature-humidity probes attached to a sensor (model KIMO TH110). The temperature- humidity probes are located in the ducts next to the temperature probes. All the air ducts of the testing rig are thermally insulated by amineral wool insulation. A photo of the testing rig can be seen in Fig 2 . 


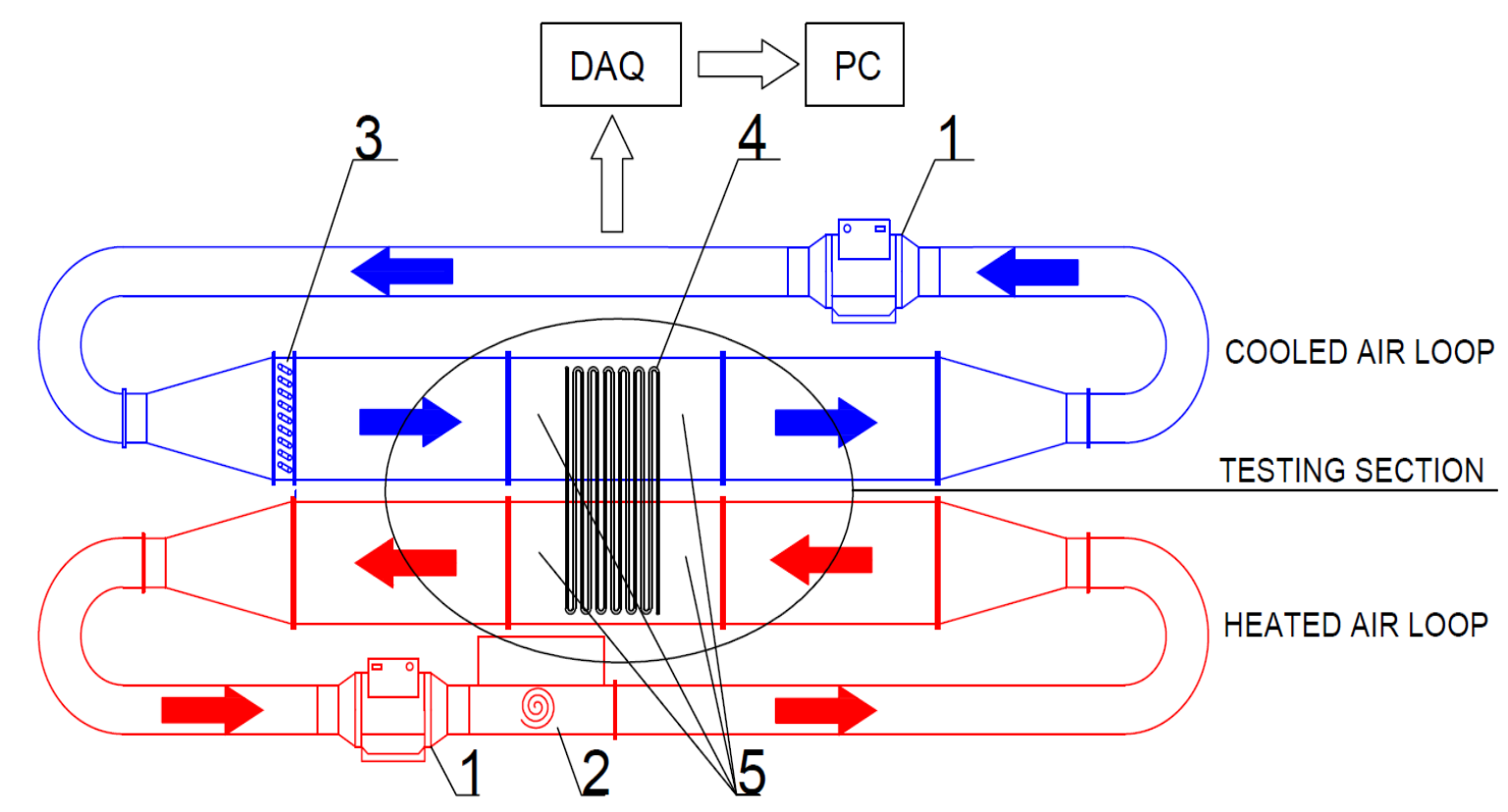

Fig. 1 Schematic of the HVAC testing rig. 1- radial fans, 2- electric heater, 3- finned tube heat exchanger, 4- ML-OHPHE, 5- thermocouples and temperature-humidity probes positions

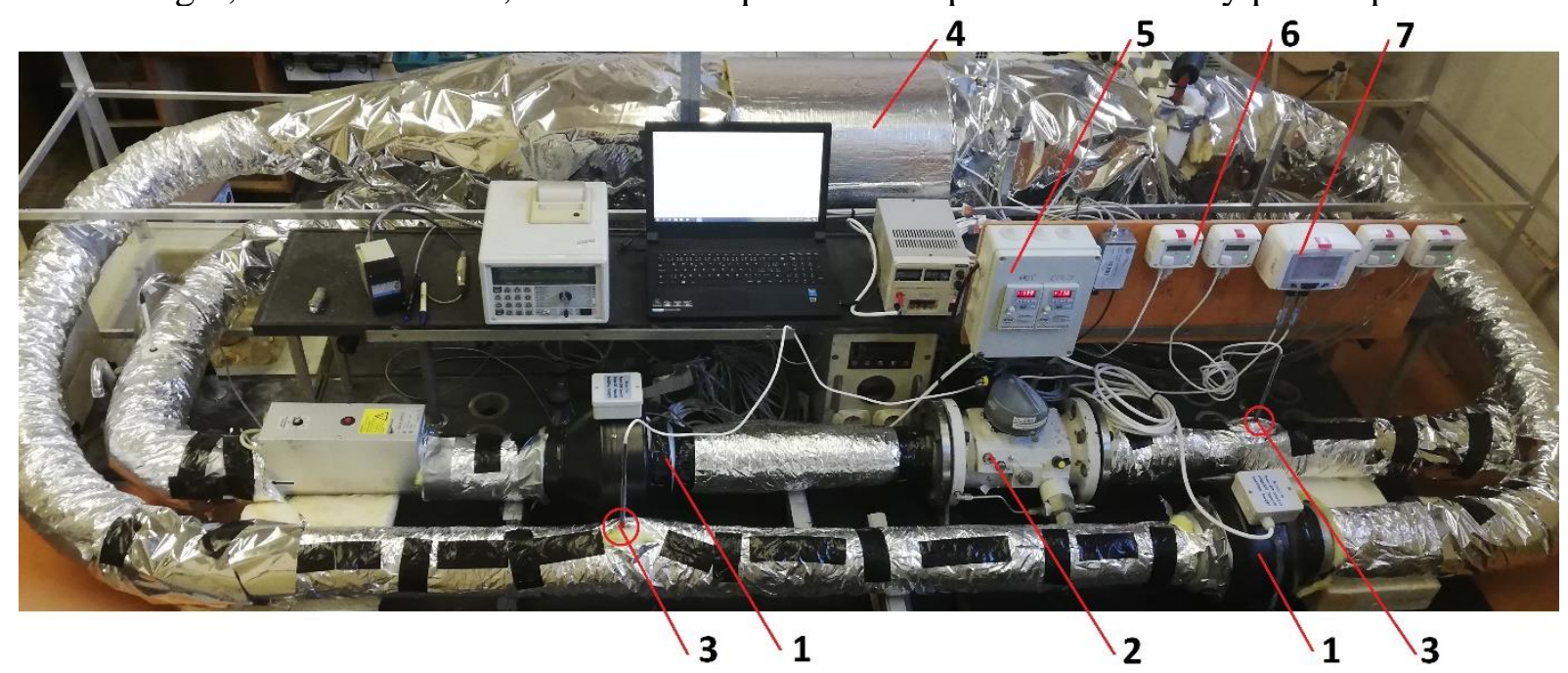

Fig. 2 Photo of the testing rig. 1- radial fans, 2- turbine flow meter, 3- hot-wire air velocity probes, 4- testing section, 5- frequency converters, 6- temperature- humidity sensors (KIMO TH110), 7- multifunction sensor (KIMO C310)

\section{The ML-OHP heat exchanger}

The maximum internal diameter of the OHP tubes strictly depends on the critical value of the Bonds number Bo [9] by the Eq. (1) as follows:

$$
D_{\text {crit }}=B o \sqrt{\frac{\sigma}{g\left(\rho_{l}-\rho_{g}\right)}},
$$

where $\sigma$ is the working fluid surface tension, $g$ is acceleration due to gravity, $\rho_{l}$ and $\rho_{g}$ is the density of the working fluid in liquid and vapour phase, respectively. Generally accepted critical value of Bonds number is $B o=2$. Thermo-physical properties of the used working fluid and critical diameter of the OHP tubes are shown in Table 1. 
Tab.1: Thermo-physical properties of diethyl ether at $20^{\circ} \mathrm{C}$

\begin{tabular}{lc}
\hline working fluid & diethyl ether \\
\hline surface tension $(\mathrm{N} / \mathrm{m})$ & 0.018 \\
\hline liquid density $\left(\mathrm{kg} / \mathrm{m}^{3}\right)$ & 713 \\
\hline vapour density $\left(\mathrm{kg} / \mathrm{m}^{3}\right)$ & 3.13 \\
\hline critical diameter $(\mathrm{mm})$ & 3.2 \\
\hline
\end{tabular}

The ML-OHP heat exchanger placed vertically in the testing rig ducts is schematically illustrated in Fig. 3. The heat exchanger is made up glass capillary tubes (ID $\varnothing 2 \mathrm{~mm}$, ODØ $6 \mathrm{~mm})$. The individual tubes are connected together by the U-shaped bent glass pieces. The lengths of the evaporating and condenser sections are identical- $190 \mathrm{~mm}$ and the length of the adiabatic section is $40 \mathrm{~mm}$. The multi-layered OHP heat exchanger consist of 8 interconnected layers (rows) totally. The distance between layers is $15 \mathrm{~mm}$. Each layer contains 10 individual tubes so the heat exchanger tubes are ordered into the $8 \times 10$ matrix. The total heat exchanger inner working volume is roughly $100 \mathrm{ml}$ and the sum of the adiabatic and condenser section heat exchange area is $0.573 \mathrm{~m}^{2}$. The calculated heat exchange area is related to the outer diameter of the tubes [19].

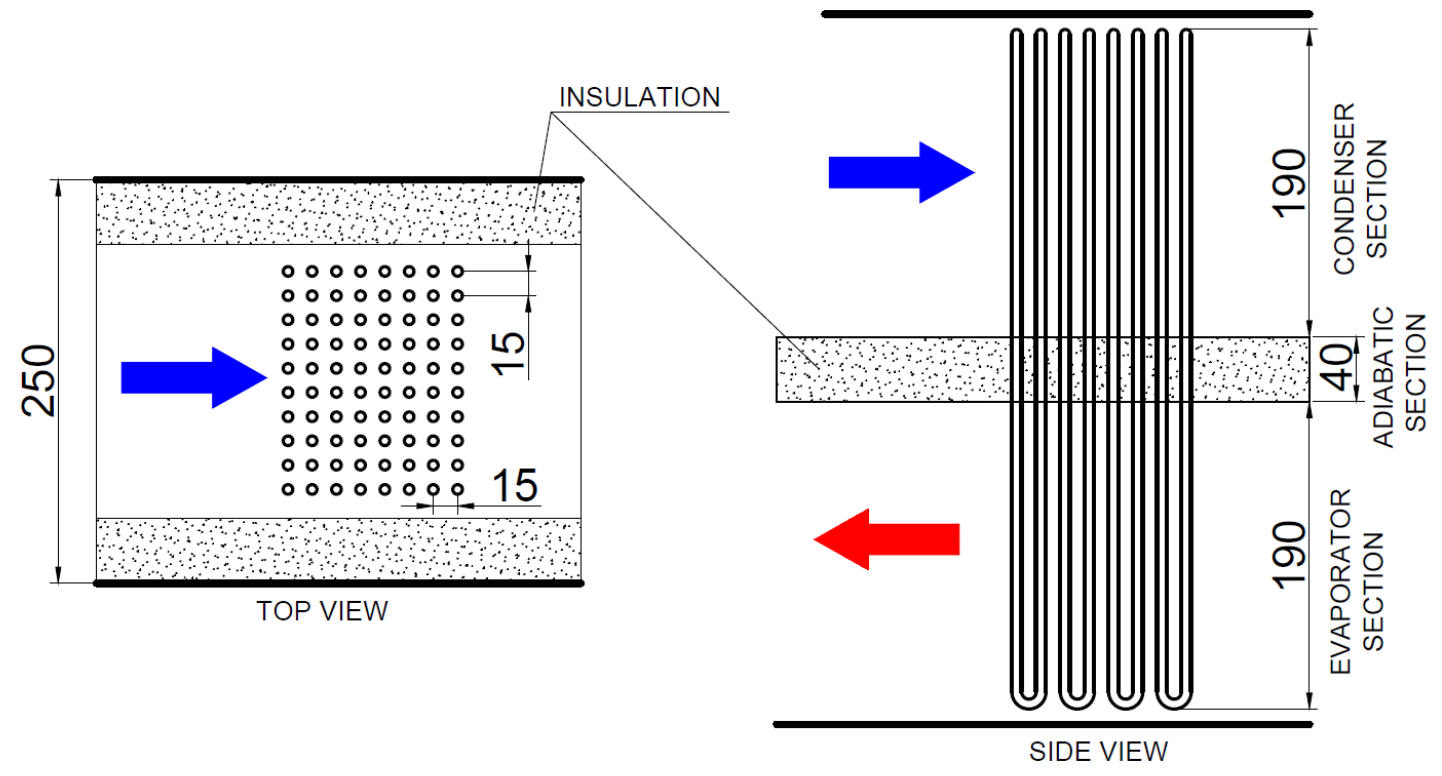

Fig. 3 Schematic of the OHP heat exchanger placed in the testing rig

\section{Experimental procedure}

The working volume of the ML-OHP heat exchanger was firstly evacuated through a vacuum port using rotary vane pump (EDWARDS RV3) as it can be seen in Fig. 4a). Then the vacuum port was sealed and the ML-OHP heat exchanger was filled with required amount of the working fluid through a filling port using a syringe. After the working fluid emptied the syringe the filling port was sealed. The working fluid immediately filled the whole working volume of the ML-OHPHE and formed into a train of separate vapour bubbles and liquid plugs as it can be seen in Fig. 4b). The required value of the filling ratio was controlled by measuring the weight of the heat exchanger before and after filling procedure. The heat exchanger was placed into the testing section of the HVAC testing rig and the required values of the air volume flow rates in the both loops were set by the frequency converters. 


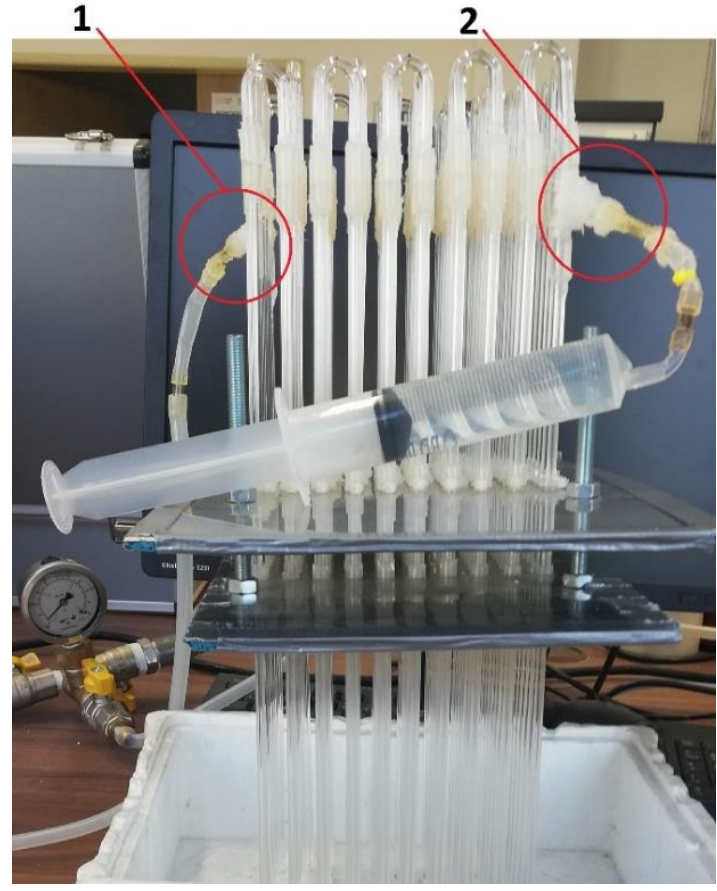

a) Location of the vacuum port (1) and filling port (2)

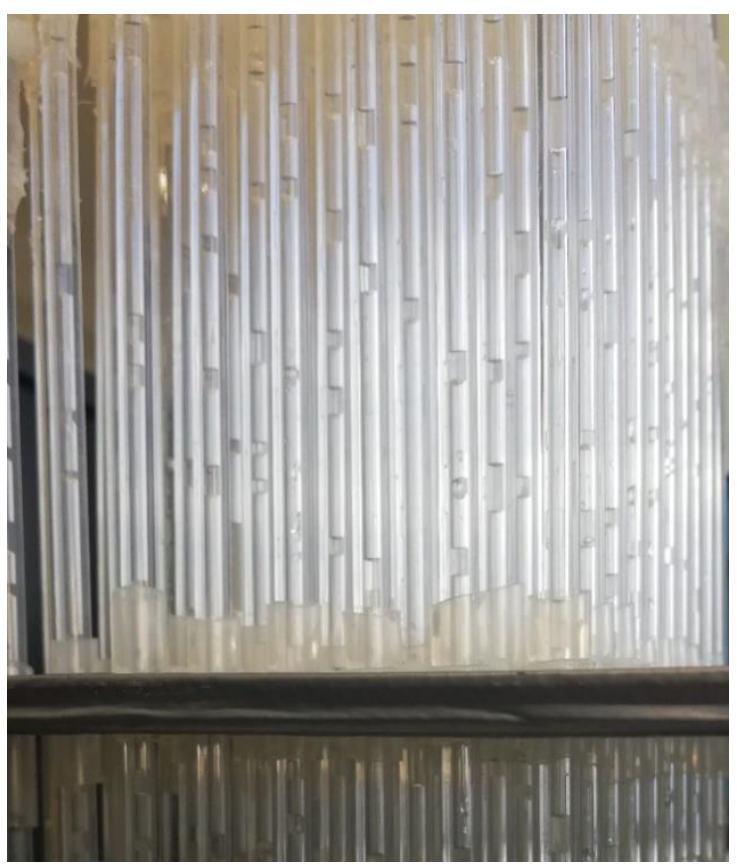

b) Detail look at the vapour bubbles and liquid plugs formed in the ML-OHPHE.

Fig. 4 Preparation procedure of the ML-OHPHE for the experiments.

\section{$5 \quad$ Results and discussion}

The ML-OHP heat exchanger heat transfer capability was tested during 12 different experiments which included 3 different cooled air volume flow rates $\left(80( \pm 1.0) \mathrm{m}^{3} / \mathrm{h}\right.$, $100( \pm 1.0) \mathrm{m}^{3} / \mathrm{h}$ and $\left.120( \pm 1.0) \mathrm{m}^{3} / \mathrm{h}\right)$ and 3 different values of the filling ratio $(25( \pm 1.0) \%$, $50( \pm 1.0) \%, 65( \pm 1.0) \%)$ for each air volume flow rate plus 3 experiments with the emptied ML-OHP heat exchanger ( $0 \%$ filling ratio). The air volume flow rate in the heated air loop was set to constant value $\left(100( \pm 1.0) \mathrm{m}^{3} / \mathrm{h}\right)$ for every experiment.

Typical air temperature response measured during experiments is shown in Fig. 5. An inlet hot air temperature entering the ML-OHP heat exchanger in the heated air loop (HOT_IN) and an inlet cold air temperature entering the ML-OHP heat exchanger in the cooled air loop (COLD_IN) were set for each experiment to $30^{\circ} \mathrm{C} \pm 0.5$ and $4^{\circ} \mathrm{C} \pm 0.5$ respectively. As it can be seen in Fig. 5 it took roughly 30 to 40 minutes until system reached steady temperature conditions in both loops.

The heat transferred by the heat exchanger was firstly calculated as the enthalpy change of the dry air in the both loops from Eq. (2) and (3) as follows:

$$
\begin{gathered}
\dot{Q}_{\text {hot }}=\dot{V}_{\text {hot }} \rho_{\text {hot }} \bar{c}_{p, \text { hot }}\left(\Delta T_{\text {hot }}\right), \\
\dot{Q}_{\text {cold }}=\dot{V}_{\text {cold }} \rho_{\text {cold }} \bar{c}_{p, \text { cold }}\left(\Delta T_{\text {cold }}\right),
\end{gathered}
$$

where $\dot{V}_{\text {hot }}$ and $\dot{V}_{\text {cold }}$ are the air volume flow rate in heated and cooled air loop, respectively. Temperature differences $\Delta T_{\text {hot }}$ and $\Delta \mathrm{T}_{\text {cold }}$ represent the mean value of the air temperature difference after reaching steady conditions in heated and cooled air loop, respectively, and can be calculated as follows:

$$
\Delta T_{h o t}=\bar{T}_{h o t, I N}-\bar{T}_{h o t, O U T}
$$




$$
\Delta T_{\text {cold }}=\bar{T}_{\text {cold }, \text { oUT }}-\bar{T}_{\text {cold,IN }}
$$

where $\bar{T}_{\text {hot,IN }}$ and $\bar{T}_{\text {hot,ouT }}$ represent a mean values of the inlet and outlet temperatures of the air in the heated air loop, respectively, and $\bar{T}_{\text {cold,IN }}$ and $\bar{T}_{\text {cold,ouT }}$ represent a mean values of the inlet and outlet temperatures of the air in the cooled air loop, respectively. These mean temperatures were calculated as the arithmetic mean values from the set of temperatures measured during steady temperature conditions.

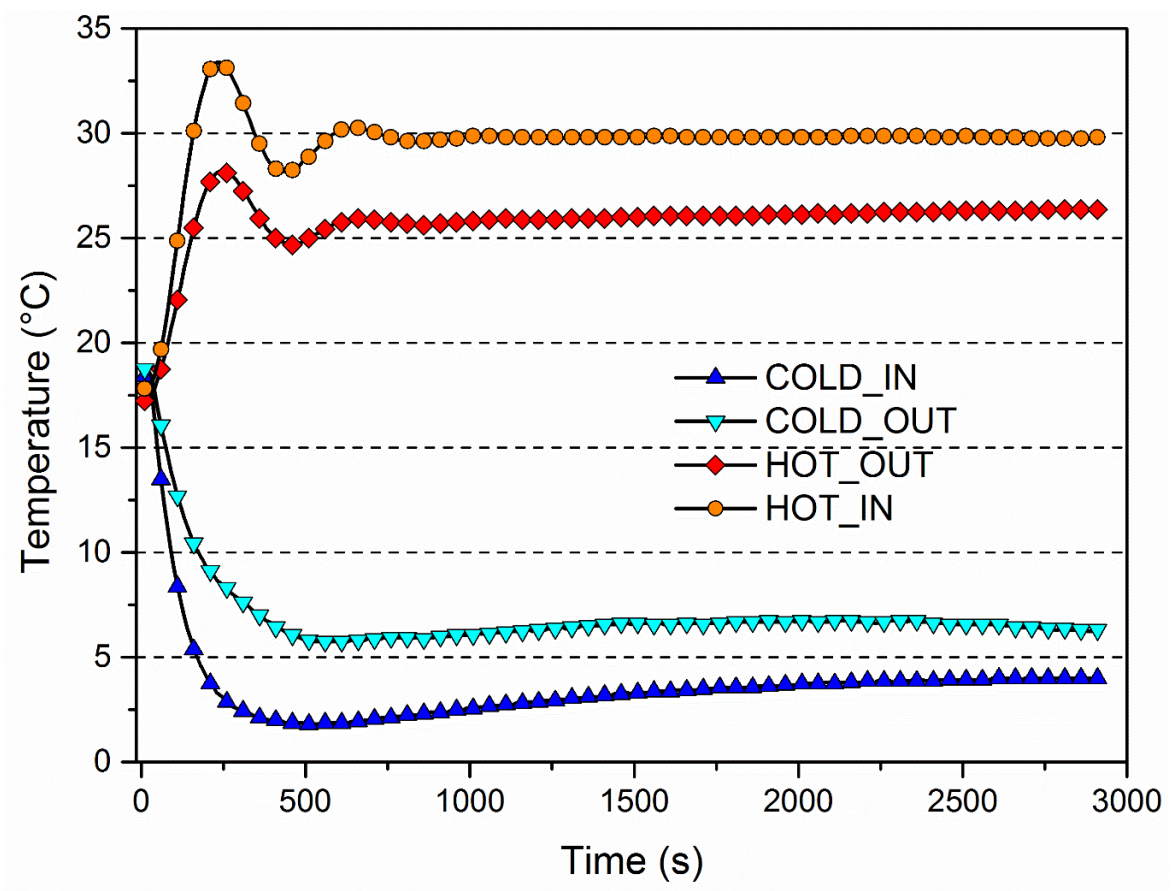

Fig. 5 Air temperatures entering and leaving the OHP heat exchanger in both loops of the rig ( $25 \%$ filling ratio, $100 \mathrm{~m}^{3} / \mathrm{h}$ volume flow rate of cooled air)

Used air properties given by density $(\rho)$ and mean value of specific heat capacity $\left(\bar{c}_{p}\right)$ referred to corresponding temperatures. The heat transferred from hot air $\left(\dot{Q}_{h o t}\right)$ was for every experiment roughly $10 \%$ higher than the heat received to cold air $\left(\dot{Q}_{c o l d}\right)$. This was caused mainly because of the heat dissipation and heat loses. Fig. 6 shows the heat transferred by the ML-OHP heat exchanger for every experiment calculated as a mean value of the heat transferred from the hot air and the heat received by the cold air $\dot{Q}=\left(\dot{Q}_{\text {hot }}+\dot{Q}_{\text {cold }}\right) / 2$.

First experiments were aimed to investigate empty ML-OHP heat exchanger $(0 \%$ filling ratio) and were necessary for evaluating heat losses of the system and heat transferred by conduction of the tubes glass walls. As it can be seen in Fig. 6 the heat transferred during 0\% filling ratio experiments did not exceed $10 \mathrm{~W}$ what indicates that the testing rig is sufficiently thermally insulated and the any further heat transfer values measured during experiments with filled ML-OHP heat exchanger should represent the heat transferred only by the oscillations of the working fluid.

The effect of the working fluid oscillations was observed immediately after the experiments started. The working fluid oscillated stable during every experiment what was controlled visually. As it can be seen in Fig. 6 the best heat transfer performance was observed for every tested cooled air loop air flow during experiments with the filling ratio of $50 \%$ followed by $65 \%$ filling ratio and $25 \%$ filling ratio. No stronger effect of the different cooled air volume flow rates on the heat transfer performance was observed. For the given 
value of the filling ratio the values of transferred heat stayed approximately constant for every cool air volume flow rate.

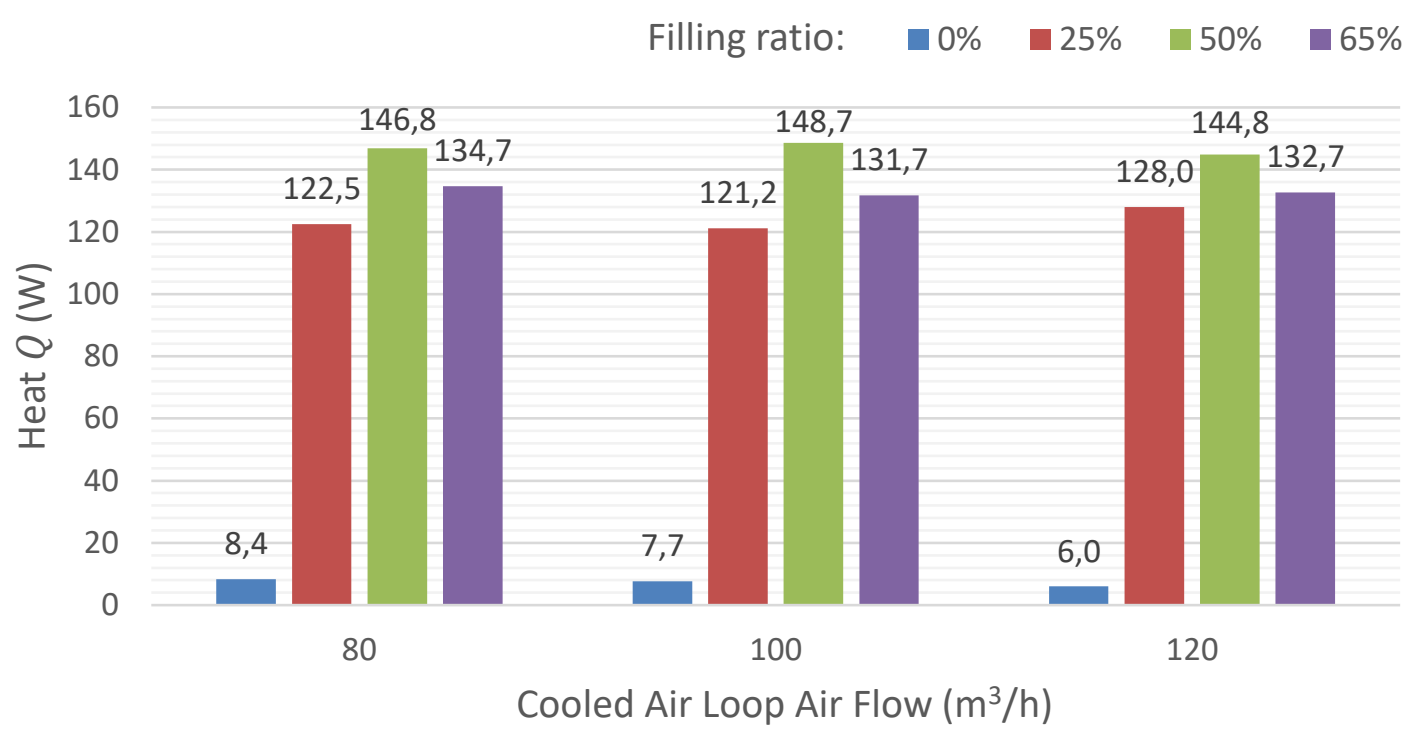

Fig. 6 The heat transferred by the ML-OHP heat exchanger calculated as the enthalpy change of the dry air.

The data calculated based on Eq. (2) and (3) were later compared with a data obtained from the Honeywell's UniSim ${ }^{\circledR}$ Design Suite software. In this case the heat transferred by the heat exchanger was calculated by the software as the enthalpy change of the moist air. A specific humidity of the air in the both loops was calculated for every experiment from a relative humidity and temperature measured by the temperature-humidity probes and sensors. The specific humidity during experiments ranged around $3 \mathrm{~g} / \mathrm{kg}$. The heat transferred by the ML-OHPHE calculated by the UniSim ${ }^{\circledR}$ Design Suite software can be seen in Fig 7. As the specific humidity of the moist air for every experiment was relatively low the calculation errors caused by neglecting air humidity did not exceed $0,5 \%$.

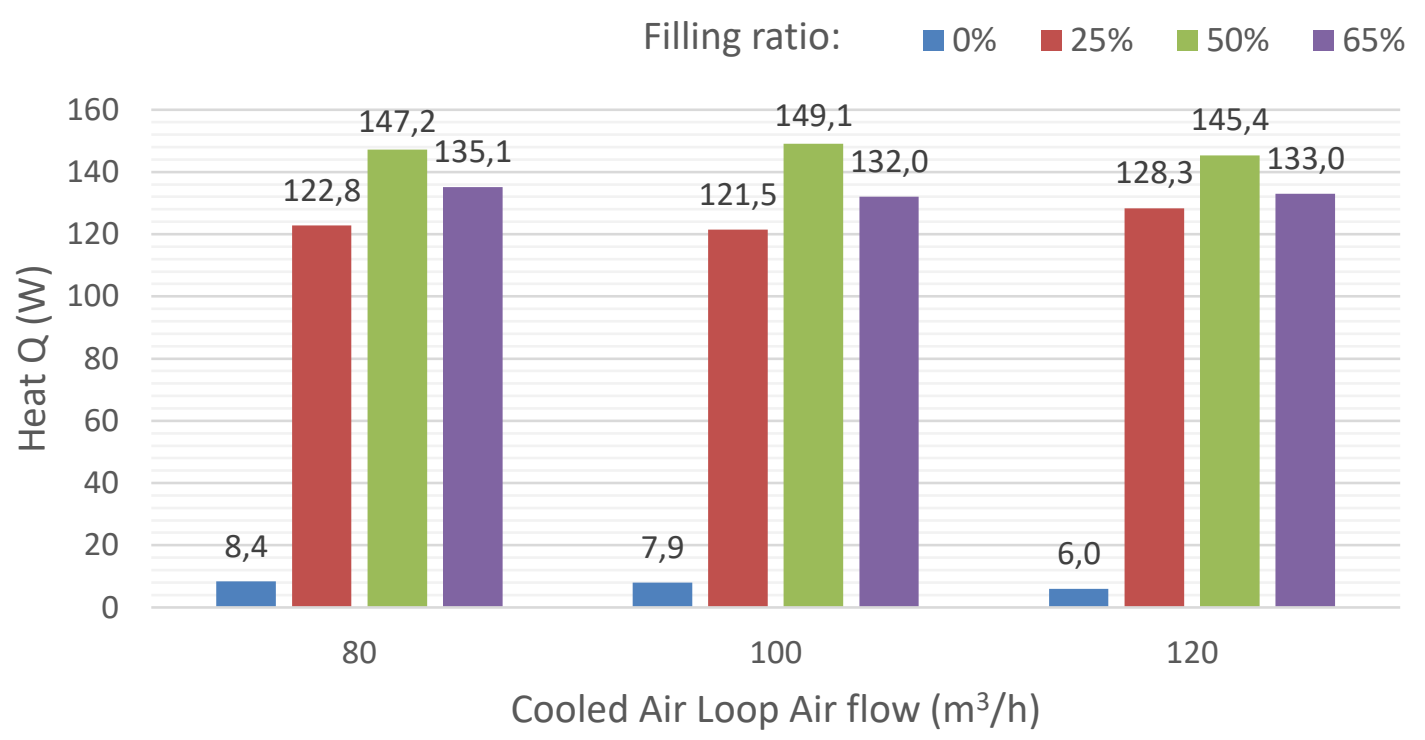

Fig. 7 The heat transferred by the ML-OHP heat exchangercalculated as the enthalpy change of the moist air given by the UniSim ${ }^{\circledR}$ Design Suite software. 
In general, recuperative heat exchangers are commonly described by the values of heat capacity rate ratio $(R)$, dimensionless temperature change $(P)$ and number of transfer units $(N T U)$. The values of $R, P$ and NTU are related to a so-called weak stream (the stream with the lower value of a heat capacity) $[19,20]$ commonly indicated by subscript 1 . Based on the experimental data, the values of the dimensionless temperature change $P_{1}$ and heat capacity rate ratio $R_{1}$ ranged as follow: $P_{1} \in\langle 0.141 ; 0.176\rangle$ and $R_{1} \in\langle 0.826 ; 0.959\rangle$. Another necessary value used during every recuperative heat exchanger design calculation is represented by a logarithmic mean temperature difference correction factor $\left(\varepsilon_{\Delta \bar{T}}\right)$. For any combination of $R_{1}$ and $P_{1}$ values calculated from the experimentally measured data in this article the value of $\varepsilon_{\Delta \bar{T}}$ is approximately equal to $1\left(\varepsilon_{\Delta \bar{T}} \approx 1\right)$ [20]. When the value of logarithmic mean temperature difference correction factor was obtained, the number of transfer units $N T U_{1}$ was calculated. The values of $N T U_{1}$ ranged as follows: $N T U_{1} \in\langle 0.157 ; 0.227\rangle$. Based on the $N T U_{1}$ values the overall heat transfer coefficient $(k)$ of the ML-OHPHE was calculated. These values ranged as follows: $k\left[\mathrm{~W} /\left(\mathrm{m}^{2} \mathrm{~K}\right)\right] \in$ $\langle 8.737 ; 11.425\rangle$.

\section{CONCLUSION}

This article proves the possibility of using diethyl ether filled ML-OHP heat exchanger serving as a passive air-to-air heat recovery heat exchanger. The experiment results prove that onset of stable oscillations of the working fluid heavily increases the heat transfer performance compared to the empty heat exchanger.

The experiments with different filling ratio values showed the dependence of the heat transfer performance on the filling ratio. The best heat transfer performance was observed during $50 \%$ filling ratio followed by $65 \%$. The optimum filling ratio probably lies within this range what agrees with the results observed in other works mentioned in the introduction [1215]. Although there definitely exists some dependence of the ML-OHP heat exchanger heat transport capability on the cooling air volume flow, any significant change was not observed within the tested range of air volume flow rates.

The results given by the calculation of the change of the dry air enthalpy were in very good agreement with the results calculated by the UniSim ${ }^{\circledR}$ Design Suite software. It can be said that within the measured range of the air humidity the calculation error caused by neglecting air humidity is negligible.

This work provides the basic heat transfer capability measurements of the ML-OHP heat exchanger in air-to-air heat transfer application and a quick approach to the NTU analysis of this type of heat exchanger. Further research in this field should be aimed to testing the heat exchanger in the wider range of different process conditions, mainly filling ratios and heat loads and developing more detailed look at NTU analysis what could possibly lead to a tool serving for design calculations of OHP heat exchangers.

\section{ACKNOWLEDGMENT}

This article was created with the support of the Ministry of Education, Science, Research and Sport of the Slovak Republic within the Research and Development Operational Programme for the project "University Science Park of STU Bratislava", ITMS 26240220084, co-funded by the European Regional Development Fund.

The authors wish to acknowledge the Scientific Grant Agency of the Ministry of Education, Science, Research and Sport of the Slovak Republic and the Slovak Academy of Sciences for the financial support of this research by grant VEGA 1/0276/17. 
This article was created within the grant project "Utilization of pulsating heat pipes for energy recovery in air conditioning" within The program of support for young researchers at the Slovak University of Technology.

The authors wish to thank to the EPH Foundation and their grant program "Projektvedátor" for the financial support within the grant project: "Experimental study of the oscillating heat pipes heat exchanger prototype in the application of heat recovery in HVAC systems".

\section{REFERENCES}

[1] Peciar, P., Fekete, R., Peciar, M. "Procesné strojníctvo II", STU, Bratislava, Slovakia, p. 177, 2016. ISBN: 978-80-227-4540-6 (in Slovak)

[2] Akachi. H. "Structure of a heat pipe“, US Patent No. 4921041.1990

[3] Ma, H. B. "Oscillating Heat Pipes.Springer“, 2015. ISBN 978-1-4939-2503-2

[4] Yang, H., Khandekar, S., Groll, M. "Performance characteristic of pulsating heat pipes as integral thermal spreader", International Journal of Thermal Sciences 48, pp. 815 824, 2009. DOI:10.1016/j.ijthermalsci.2008.05.017

[5] Supirattanakul, P., Rittidech, S., Bubphachot, B. "Application of a closed-loop oscillating heat pipe with check valves (CLOHP/CV) on performance enhancement in air conditioning system“, Energy and Buildings 43 (7), pp. 1531 - 1535, 2011. DOI:10.1016/j.enbuild.2011.02.017

[6] Meena P., Rittidech S., Poomsa-ad, N. "Application of closed-loop oscillating heat pipe with check valves (CLOHP/CV) air-preheater for reduce relative-humidity in drying systems“, Applied Energy 84, pp. 553 - 564, 2007. DOI: 10.1016/j.apenergy.2006.09.006

[7] Rittidech, S., Dangeton, W., Soponronnarit, S. "Closed-ended oscillating heat pipe (CEOHP) air-preheater for energy thrift in a dryer", Applied Energy 81, pp. 198 - 208, 2005. DOI: $10.1016 /$ j.apenergy.2004.06.003

[8] Mahajan, G., Thompson, S. M., Cho, H. "Energy and cost saving potential of oscillating heat pipes for waste heat recovery ventilation”, Energy Reports 3, pp. 46 - 53, 2017. DOI:10.1016/j.egyr.2016.12.002

[9] Mahajan, G., Cho, H., Thompson, S. "Oscillating heat pipes for waste heat recovery in HVAC systems", Proceedings of the 15th International Mechanical Engineering Congress \& Exposition, 2015. DOI: 10.1115/IMECE2015-52720

[10] McCullough, Ch. R., Thompson, S. M., Cho, H. "Heat recovery with oscillating heat pipes", Proceedings of the ASME 2013 International Mechanical Engineering Congress and Exposition, 2013.

[11] Khandekar, S. "Pulsating heat pipe based heat exchanger", The 21st International Symposium on Transport Phenomena, 2010.

[12] Shahare, P. V., Jain, K. K. "Review of unsolved matter related to pulsating heat pipes", International Journal of Mechanical Engineering and Robotics Research, 2012

[13] Barua. H., Ali. M., Md. Nuruzzaman, Islam, M. Q., Feroz Ch. M. "Effect of filling ratio on heat transfer characteristics and performance of a closed loop pulsating heat pipe", Procedia Engineering 56, pp. 88 - 95, 2013. DOI: 10.1016/j.proeng.2013.03.093

[14] Zhao, J., Qu, J., Rao Z. "Experimental investigation on thermal performance of a largescale oscillating heat pipe with self-rewetting fluid used for thermal energy storage", 
International Journal of Heat and Mass Transfer 108, pp. 760 - 769, 2017. DOI: 10.1016/j.ijheatmasstransfer.2016.12.093

[15] Yin, D., Rajab, H., Ma, H. B. "Theoretical analysis of maximum filling ratio in an oscillating heat pipe", International Journal of Heat and Mass Transfer 74, pp. 353 357, 2014. DOI: 10.1016/j.ijheatmasstransfer.2014.03.018

[16] Qu, J., Zhao, J., Rao, Z. "Experimental investigation on thermal performance of multilayers three-dimensional oscillating heat pipes", International Journal of Heat and Mass Transfer 115, pp. 810 - 819, 2017. DOI: 10.1016/j.ijheatmasstransfer.2017.08.082

[17] Mahajan, G., Thompson, S. M., Cho, H. "Experimental characterization of an n-pentane oscillating heat pipe for waste heat recovery in ventilation systems", Heliyon 4, 2018. DOI: 10.1016/j.heliyon.2018.e00922

[18] Kapilan, N., Manjunath, M., Manjunath, H. N. "Computational fluid dynamics of an evaporative cooling system", Journal of Mechanical Engineering - Strojnícky časopis 66 (2), pp. 117 - 124, 2016. DOI: 10.1515/scjme-2016-0026

[19] Gužela, Š., Dzianik, F., Juriga, M., Kabát J. "Shell and tube heat exchanger- the heat transfer area design process", Journal of Mechanical Engineering - Strojnícky časopis 67 (2), pp. 13 - 24, 2017. DOI: 10.1515/scjme-2017-0014

[20] Gužela, Š., Dzianik F. "Some facts resulting from the key variables used in the description of the recuperative heat exchangers", Journal of Mechanical Engineering Strojnícky časopis 68 (3), pp. 249 - 260, 2018. DOI: 10.2478/scjme-2018-0038 